\title{
Do We Follow the Leader or the Masses? Antecedents of the Willingness to Pay Extra for Eco-Products
}

\author{
Helen Arce Salazar and Leon Oerlemans
}

\begin{abstract}
This paper reports on an experiment that tests for the existence of peer effects in consumers' willingness to pay (WTP) for sustainable products. More specifically, we investigate whether the premium for an eco-labeled laundry detergent is sensitive to receiving information about the premium paid by other members of one's social group. The infor-mation manipulations in the experiment test for two distinct types of social influence, i.e., conformist and payoff-biased transmission. We find strong empirical evidence for a conformist transmission. Participants informed about the positive premium paid by the majority of their peers reported a higher premium than individuals not receiving any informa-tion. This result shows that previous studies on the WTP for sustainable products, which explain premiums by attitudinal measures and sociode-mographic traits, unwarrantedly provide an under-socialized account. The inclusion of social influence variables significantly increases the explanatory power of the model.
\end{abstract}

In the last two decades, the supply of eco-products and eco-labels has emerged as a response to growing consumer demand for products that are regarded more sustainable. As a result, many studies have been conducted analyzing the willingness-to-pay (WTP) for products with social and/or ecological characteristics. The majority of these studies find that a large group of participants is willing to pay a relatively high premium for sustainable products, starting at an additional $10 \%$ extra for disposable products and reaching up to a $35 \%$ premium for ingestible products such as fresh meats, seafood, and fruits and vegetables (e.g., Bjørner, Hansen, and Russell 2004; Cason and Gangadharan 2002; Hopkins and Roche 2009; Loureiro and Hine 2002; Loureiro, McCluskey, and Mittelhammer 2002;

Helen Arce Salazar (arcesala@uvt.nl) is a Lecturer in Department of International Business and Management Studies, The Hague University of Applied Sciences, The Hague, The Netherlands. Leon Oerlemans (1.a.g.oerlemans@uvt.nl) is a Professor of Organizational Dynamics, Department of Organization Studies, Tilburg School of Social and Behavioral Sciences, Tilburg University, The Netherlands, and an Extraordinary Professor of Economics of Innovation, Department of Engineering and Technology Management, University of Pretoria, Republic of South Africa. The authors wish to thank the Fontys International Business School (FIBS) for facilitating the experiment and providing financial support. In particular we are indebted to Dr. Saskia van Stroe-Biezen for the support during the organization of the experiment. We are also grateful to two anonymous reviewers and to the participants of the $134^{\text {th }}$ EAAE conference "Labels on Sustainability: An Issue for Consumers, Producers, Policy Makers and NGOs" for their helpful comments. 
Radam et al. 2010; Roe et al. 2001; Shen and Saijo 2007). An additional finding of these studies is that most consumers express a predisposition to buy sustainable products (willingness to buy). For example, in a study of eco-labels in four locations in the US state of Colorado, Loureiro and Lotade (2005) report that $40 \%$ of the interviewed people are willing to buy sustainable products. Pelsmacker, Driesen, and Rayp (2005) present similar findings in a study conducted in Belgium.

Although these studies provide valuable insights into the size of the premium and a number of its determinants (e.g., consumers' environmental attitudes, perceived consumer effectiveness (PCE), consumers' socioeconomic characteristics, etc.), these high premium levels are not strongly reflected in similar market shares of these products. This attitude-behavior gap poses a puzzle for researchers, because it demonstrates that high levels of pro-environmental attitudes and intentions do not necessarily lead to actual purchases. Young et al. (2010) show that approximately $30 \%$ of consumers report to be highly concerned about environmental problems, but struggle to translate these positive attitudes into actual purchases.

Existing studies tend to overlook the possible influence of social relations of individuals on economic life in general and on consumers' decisions and behavior in particular (Granovetter 1985). This is unwarranted, as consumer studies focussing on non-sustainable products have built a strong evidence base showing that consumers use information from other individuals (e.g., their peers) as a reference to make individual choices and decisions (Burnkrant and Cousineau 1975). Also, they provide ample evidence that people's consumption choices are influenced by the social groups with whom they interact. For example, Childers, Haley, and Jahns (2011) report that friends have a strong influence on college freshmen's eating behavior and choices. Also, in a US study Goodrich and Mangleburg (2010) show that parents and peers have a strong impact on purchasing decisions of both luxury and necessity products. However, the perceived social influence varies with the product type under consideration. Since there is no a priori reason to assume that such peer effects would not apply to sustainable products, we conjecture that peers' predisposition to pay more/less for specific eco-products likely has an effect on an individual's WTP for such products. As a result, variables describing dimensions of the social environment of consumers can help to explain the observed variation in ethical premiums, providing some leads about the presence of an attitude-behavior gap.

Some evidence in this direction is presented by List et al. (2004), who show in a contingent valuation study that social effects can increase the 
valuation of social and environmentally friendly goods. They find that more participants are willing to contribute to an environmental organization when a random group of participants had to inform their choice to the whole group. Similarly, evidence from experimental studies shows that the presence and influence of social actors increases biddings in experimental auctions. For example, Corrigan and Rousu (2006) found that biddings increase when participants were informed that "high" past prices were paid by earlier participants. Also, Stern and Stafford (2006) find evidence of social influence, as in their study a higher number of early biddings increases the winning bid. Hence, the actions of other group members affect subsequent bidding behavior. While the latter indicates that the social environment influences the WTP of others in a social setting, it is not clear to what extent social influence plays a role in a more private setting where consumers make individual choices, but are informed about their peers' behavior. It is also unresolved whether valuation of sustainable products would be more/less susceptible to social influence than valuation of conventional ones.

Hence, in this study we aim to complement previous studies on WTP by explicitly including behavioral information from specific social groups (peers' past behavior), to test for social influence on the WTP a premium for sustainable products. With this purpose, a revealed preference experimental design, applying the $\mathrm{BDM}^{1}$ mechanism, is used to measure the size of the WTP premium under different conditions. In particular, we focus on two types of social influence: conformist transmission (following the behavior of the majority in a relevant social group), and payoff-biased transmission (following the behavior of "high status"/"well-off" people). In so doing, this study answers the following research questions: Does social influence play a prominent role in the variation in premium of sustainable products? If so, to what extent do consumers confer more weight to the signals given by the majority of their social group as compared to individuals considered having a "high status"?

\section{WTP AND ITS DETERMINANTS}

There is an extensive body of literature that tries to reveal the maximum price a buyer is willing to pay for a given quantity of a sustainable product (e.g., Aryal et al. 2009; Bjørner, Hansen, and Russell 2004; Cason and Gangadharan 2002; Hopkins and Roche 2009; Hu, Woods, and Bastin 2009; Loureiro and Hine 2002; Loureiro, McCluskey, and Mittelhammer

1. Becker-De Groot-Marschak mechanism, which is described below. 
2002; Michaud and Llerena 2011; Roe et al. 2001; Shen and Saijo 2007). While most studies on WTP focus on food products and renewable energy, in recent years a handful of studies have been published that focus on non-edible products. For example, Drozdenko, Jensen, and Coelho (2011) found that US homeowners are willing to pay a 9.5\% premium for a "green" music player and $10.4 \%$ for a hybrid car. Yue et al. (2010), in a study among consumers in the United States, also present evidence that participants were willing to pay a price premium for biodegradable plant containers. The same applies to housing, as documented in Yung (2012), where respondents demonstrate a higher WTP for green housing with sustainable attributes, especially when green housing leads to saving in utility bills or is coupled with direct economic incentives.

The majority of studies on WTP center prime attention on the influence of individual characteristics (Trudel and Cotte 2009) such as attitudes and sociodemographic characteristics, bearing witness to rigid methodological individualism (Howarth and Wilson 2006). In line with this, Michaud and Llerena (2011) and Yung (2012) show that positive attitudes toward the environment have a positive effect on the premium for sustainable products, whereas Shen (2012) finds that sociodemographic characteristics such as gender, age, education, and household income are important factors affecting consumers' WTP. However, because consumers are "social beings," there are reasons to believe that the social environment in which consumers are embedded also plays a role in their economic decisions. In the next section, we pay attention to a number of specific social influence mechanisms.

\section{SOCIAL INFLUENCE: CONFORMIST AND PAYOFF- BIASED TRANSMISSION}

Consumers, like most social actors, are influenced by their social environment (Granovetter 1985), because they interact continuously with other individuals and therefore learn from and are informed and influenced by them. This phenomenon has been labeled as social learning. However, the social environment is not a homogeneous set of actors, since individuals discriminate between different types of persons from whom they receive information. Some people are believed to have more or better information than others, and the social group with which one identifies also matters. Therefore, people tend to confer different weights to information from specific individuals or groups (often labeled as biased social learning) (Falk and Knell 2004). In the literature on social learning, two biases or tendencies stand out. The first is the tendency for individuals to adopt the 
most common behavior in the population, which is called "conformist transmission." This effect is the result of an overwhelmingly large assortment of products and information, where consumers face choice difficulties because of their bounded rationality and the high search costs that would emerge if the consumer has to find all relevant information himself. For efficiency reasons, consumers tend to focus on products demanded or chosen by the majority without carefully examining and processing all available information (Henrich and Boyd 1998, 2001). Second, a tendency has been documented in which consumers follow the behavior of individuals who are perceived of having "high status," also known as "payoff-biased transmission" (Henrich and Boyd 2001). This propensity is the result of a learning process where there is a (perceived) information asymmetry and high uncertainty about possible payoffs, and where consumers focus on choices of "high status" individuals. These subjects are considered to have the reputation of being highly skilled or knowledgeable, and therefore their actions are regarded as better informed and associated with higher payoffs and/or lower uncertainty. Furthermore, one may follow their actions to feel associated with them directly and thereby with their success (a so-called halo effect).

Although both mechanisms have been widely studied, particularly in studies of technology adoption (e.g., Efferson et al. 2007; Weeds 2012), in WTP studies there are relatively few empirical examples of specific transmission channels for peer effects. A more direct confrontation between individual and group choices is elicited in a study by Demont et al. (2012a) on consumer valuation of rice produced with different technologies in Benin. In this study, the interpersonal influence (social dimension) is introduced in the form of a collective/consensus valuation. After giving an individual valuation of different types of rice, participants were grouped and assigned to come up with a collective valuation (collective WTP) of the products. In this way, they provide a mechanism for pooling participants' knowledge, expertise, and preferences. The aim of this study was to observe a possible difference between the individual and collective WTP (considered a socially acceptable price). However, no systematic difference was revealed in the study, nor in a follow-up study in Senegal (Demont et al. 2012b). In the experimental field, studies often pay attention to the social component in the determination of the WTP but fail to isolate the effect that different types of relevant others exert on WTP. Nor do they zoom in on the effect of information coming from specific social peer groups or persons on individual WTP. This presents a clear gap to be filled in our knowledge about the WTP for sustainable products. 
We aim to make a contribution to closing this gap explicitly differentiating between the influence of one specific "high status" individual and the group's majority, because evidence from consumer studies shows that consumers differ regarding their preference for sources of information (Bearden, Netemeyer, and Teel 1989) and assign different weights to information coming from specific individuals in a social group. In some cases, consumers follow the suggestions of other typical consumers (peers, acquaintances, or co-workers) rather than the opinion of an expert (Chen 2008), because they are regarded as similar individuals with whom they easily identify themselves. This "sameness" offers them a sense of belonging. Moretti (2011) illustrates this for people's decisions about which movies to visit. Using box-office data for all movies released between 1982 and 2000, he shows that the selection of movies depends on information individuals receive from their peers. Thus, peers provide individuals with norms, attitudes, and values (Kelley 1947) and are regarded as normative referents. In other cases, consumers consider adopting products on the basis of information given by specific "high status" individuals that are regarded as more skilled, knowledgeable, or successful (Goldenberg et al. 2009). This strategy allows consumers, at least in perception, to differentiate themselves from the majority in the group and increase their social standing (comparative influence). For example, Dubois and Duquesne (1993) showed evidence that the higher the income of an individual, the higher the propensity to purchase expensive/luxury goods to signal his or her success. Thus, "high status" individuals provide standards of achievement (Childers and Rao 1992).

To analyze whether the information provided by groups and specific group members affects individual premiums, we design different experimental treatments where individual participants receive written information about the premiums paid by their peers (co-workers in our case) and, subsequently, they have to make a valuation of sustainable products themselves. Since normative influence requires some level of interaction to enable the group to evaluate the desirability of individual conformity to the group's norms (Cocanougher and Bruce 1971), co-workers seem an appropriate reference point for the experiment. Colleagues tend to spend many hours together and interact on a daily basis, which should provide ample opportunity to exchange information and views about socially acceptable issues and products, including environmentally responsible products and behaviors.

The participants for our experiment are recruited from an institute for higher education. As "high status" referents, we selected the "managers" of two of the study programs that the institute offers, where each program 
involves a team of about 50 individuals under the direction of a specific person ("team manager"). The assumption is that "team managers" are important referents because of their competence and superior decision-making power in the professional sphere, and that this influence spills over to other domains. It has been shown that individuals in executive and managerial positions tend to act as role models for employees interacting with them and provide guidance for what is considered acceptable ethical behaviors (Chen, Sawyers, and Williams 1997; Valentine and Barnett 2002). Hence, due to their central position and continuous interaction with external individuals and employees, they qualify as powerful "opinion leaders." Subordinates look for cues of appropriate behavior in superiors and tend to emulate them (Pearce, Kramer, and Robbins 1997). For example, Filstad (2004) illustrates how new employees are influenced by their socialization with colleagues and supervisors at different levels. In the marketing literature, many studies find that "opinion leaders," influential people, or "hubs" (a term used in social network studies to indicate highly connected individuals) are the ones who exert more influence than others because of their reputation, expertise and credibility, or authority and status and popularity (Goldenberg et al. 2009; Katz 1957).

In the experiment we manipulated the information that participants receive about the stated WTP of the manager of the team to which one belongs. To assess the level of transferability of this manipulation, a pilot survey was conducted two months prior to the experiment among 45 respondents, who were requested to state their perception about the environmentally friendliness of a set of products. The aim was to gauge the level of attention paid to different information sources, i.e., to assess the relative importance of different personal referents. The importance of such "attentional carriers" within organizations has been demonstrated by Ocasio (2011). In this pilot, part of the respondents (20 individuals) were presented a flyer providing a short definition of sustainable innovation and depicting one of three products that have become more sustainable over the years (fish, toilet paper, and LED lamps) and these were presented by either one of three co-workers (the team manager, a senior researcher/lecturer with expertise in sustainability topics, or a lecturer of didactics). ${ }^{2}$ Others (25 individuals) did not receive this stimulus. The comparison of respondents with and without stimulus showed a slight perceptual difference in favor of the environmental friendliness of the products, but only when the

2. The selection of the subjects presenting the products was informed by the rank employees are believed to occupy in the organizational structure of the higher education institution. All three were approached to provide their consent for the flyer and to select the product they preferred. 
flyer was presented by the highest ranked co-worker, i.e., the team manager. $^{3}$ In our main experiment we tried to enhance the credibility of the information supplied about the team manager through a subtle reputational scan of managers concerning their commitment to sustainability.

The above results in the following set of hypotheses, each of which corresponds to a treatment in the experiment.

H1: Participants informed that the majority of their peers paid more for the eco product will reveal a higher premium for this product than individuals not receiving such information (conformist transmission toward sustainable products).

H2: Participants informed that the majority of their peers paid more for the non-eco product, will reveal a higher premium for this product than individuals not receiving such information (conformist transmission toward non-sustainable products). Therefore, the premium for sustainable products paid in this group will be lower than or equal to the premium of participants not receiving any information.

It should be noted that the effects for $\mathrm{H} 1$ and $\mathrm{H} 2$ are not necessarily symmetric or equally large, because the informational effects may differ per product (eco and non-eco laundry product).

H3: Participants informed that a "high status" person in their group paid more for the eco product will disclose a higher WTP for this product than participants not receiving any information (payoff-biased transmission toward sustainable products).

H4: Participants informed that a "high status" person in their group paid more for the non-eco product will disclose a higher WTP for the conventional option than participants not receiving any information (payoff-biased transmission toward non-sustainable products). As a result, the premium for the sustainable product might not be significantly different from the one paid by participants not receiving any information.

Similarly, $\mathrm{H} 3$ and $\mathrm{H} 4$ are not necessarily equally large because the influence of referent persons may again differ (in terms of the weight assigned to them), depending on whether information concerns eco or non-eco laundry products.

\section{METHOD: THE EXPERIMENTAL DESIGN}

To collect the data we make use of a revealed preference design, specifically the BDM mechanism instead of a conventional survey. The BDM mechanism is an incentive-compatible method, where each participant submits an offer price to purchase a product. Afterwards, an artificial price is randomly drawn from a distribution of prices using a number generator. The interval starts at zero and stops at some price that is believed

3. The results are presented in Tables A1.1 and A1.2 and Figure A1 of Appendix 1. 
to exceed the anticipated maximum willingness-to-pay among bidders, in our case $€ 10$. Any participant who submits a bid higher than or equal to the "sale price" receives a unit of the product. If the bid is lower than the sale price, he receives the generated amount in cash. For example, in case a participant states a valuation of $€ 6$ and the number generator displays a 5 , the rules of the game stipulate that the participant earns the product. However, if the bid is $€ 3$ and the number generator produces a 5 , then the participant would receive $€ 5$ in cash. ${ }^{4}$ This procedure encourages participants to reveal their true valuation, because untruthful answers can lead to a lower payoff..$^{5}$ This incentive-compatibility feature of the procedure is explained to all participants prior to carrying out the actual decision task.

The BDM mechanism was chosen to overcome problems related to the hypothetical nature of stated preference methods, i.e., avoid morally or politically correct answers, which would imply a possible overstatement of premiums for sustainable products. Although the BDM mechanism presents some limitations like the inducement to over-interpret the results or risks of underbidding, ${ }^{6}$ we believe that these concerns are trumped by its merits. One important advantage is that it provides participants with economic incentives in the form of small amounts of money or gift products. It is important to note that participants' payoffs depend on the decisions they make during the experiment. Thus, they are encouraged to use the available information in order to maximize their payoff. Also, the BDM mechanism was chosen over second-price auction (e.g., Vickrey auction or generalized second-price auction-GSP) because it can be used conclusively with a single participant and provides strong incentives for truthful bidding, regardless of the magnitude of their WTP (Lusk, Alexander, and Rousu 2007). In addition, this method reveals the entire distribution of individual WTPs and by bidding against a random price generator, we can avoid problems of competition between bidders (overbidding) and collusion on a maximum premium (Harrison, Harstad, and Rutström 2004).

4. $\mathrm{x} \geq p=>$ product

$\mathrm{x}<\boldsymbol{p}=>$ cash amount equal to $p$

where: $\mathbf{x}=$ participant's bidding for the product.

$p=$ price generated by the number generator.

5. Imagine a situation in which a participant provides a higher valuation than what he/she really would have paid for the product. She states a bidding of $€ 6$, while her real valuation is only $€ 3$. Then, assume the generator provides a 5. Given the rules, the participant will receive the product, which is only worth $€ 3$ to her. Note that by providing the real valuation (3), she would have won $€ 5$. A similar "loss" may occur in case of understating one's true WTP.

6. Other concerns about the method are related to reliability of the observed decision in (over) simplified situations. 
To observe whether information received about peers' premium influences the individual premium for sustainable products, the experimental setting consisted of five different "arms." In the first arm (Group 0 or control group), participants acted fully individually and did not receive any additional information about their peers. In the second arm, labeled as "Conformist transmission toward eco products" (C1) and henceforth abbreviated as treatment $C 1$, participants received manipulated information about the premium paid by, and past behavior of other participants (co-workers). The information was provided in the form of a vignette (see Figure A2 in Appendix 1), stating that the majority of previous participants (restricted to "team members") ${ }^{7}$ in the study had paid more for the eco product in comparison to the conventional one. No specific amounts or percentages were mentioned in order to avoid a premium bias toward a specific amount, which Corrigan and Rousu (2006) refer to as "bid affiliation." In this way, participants had no anchor to fix their bid to. In the third arm (Conformist transmission toward non-eco products or C2) participants also received information about the premium paid by the majority of their colleagues, but the vignette stated that the majority of previous participants had paid more for the non-eco product. During the fourth arm, labeled as "Payoff-biased transmission toward eco products or W1," instead of providing information about the past behavior of the majority of previous participants, we provided information about the past behavior of a specific "high status" individual who belongs to the participants" work department, viz., the team manager, assuming a higher hierarchical position in the organizational structure, and most likely a higher number of social ties. As explained, the identification of the "high status" individual was based on a reputation scan of the team managers. ${ }^{8}$ The information provided in this fourth arm stated that the team manager paid more for the eco product. Finally, in the fifth arm (Payoff-biased transmission toward non-eco products or W2) participants also received information about the behavior of a "high status" individual, but the vignette stated that the team manager paid more for the non-eco product. In this case the selected team

7. The terms "team" and "team manager" were used in the experiment, since these are colloquial terms used in the institution where the experiment was conducted to indicate an educational program and its director, respectively. The institution offers programs in business and marketing. Participants were recruited from both.

8. During the scan, aspects such as personal or group distinctions related to sustainability, the inclusion of sustainability goals or promotion of sustainability practices in the management plan, etc., or the absence of them were revised in an informal and subtle way with the intention of minimizing salience of this among participants. Also, the department manager/“team leader" presented a central position in the depictions collected from participants in the pilot survey. 
manager had no reputation of being a person committed to sustainability and the management plan exclusively focussed on conventional performance goals.

We define the premium for the eco product in relative terms, i.e., as mark-upon the WTP for the non-eco product and denote this as RPREMIUM. ${ }^{9}$ The relative premium is thus as follows:

$$
\text { RPREMIUM }=(\text { WTPE }- \text { WTPNE }) / \text { WTPNE }
$$

where $\mathrm{WTPE}=$ Willingness to pay for eco-product and WTPNE $=$ Willingness to pay for non-eco/conventional product.

For our analyses, we choose to use RPREMIUM as the dependent variable. This is preferred over the alternative to use the WTP for individual products, since this procedure helps to mitigate any affiliation bias during the bidding (Corrigan and Rousu 2006; Huffman et al. 2003). The main reason for conducting this analysis, however, is that the variation in the base price for the conventional product complicates an assessment of the size of the premium. By illustration, consumers may focus on a specific absolute premium, say (€1), which results in RPREMIUM being $33 \%$ in case the base price is $€ 3$, but only $20 \%$ if it is $€ 5$. To assess whether social influence variables help to explain the variance in the premium for eco-labeled products, a hierarchical multiple regression was conducted. In the regression analysis, we also add a variable that captures participants' sensitivity to other social referents (family and friends), who are not targeted in the experiment, but who are singled out by previous research as having a strong influence in the choice of brands and products (Moore, Wilkie, and Lutz 2002). This information was gathered through a question in a short post-experiment survey, as explained in the next section.

\section{PROCEDURE OF THE EXPERIMENT}

The experiment uses two existing home brand laundry products from a Dutch supermarket chain to minimize aesthetic or brand bias. Both products were similar in all respects (brand, form, quantity, concentration, etc.), except that one was a sustainable detergent (eco-labeled product) and the other was a conventional one (non-eco product). Participants had

9. We also conducted an analysis using the premium in absolute terms, amount in Euro, [WTPE -WTPNE] as dependent variable. However, given the controversy toward using difference scores as dependent variables, these results are not included, mainly to prevent the readers' attention from deviating from the peer influence on the premium level to the downsides of using difference scores. It is worth mentioning that these results do not deviate from the ones reported here. 
to examine both products and provide a valuation for both. This feature allows us to measure more accurately the WTP for each product and the subsequent premium, because the comparison highlights the products' main difference, i.e., the sustainability attribute, compared to the case where participants only report the WTP for a single eco product. Moreover, this mitigates any affiliation bias (Corrigan and Rousu 2006) and isolates the effect of any additional information related to each product. Participants had to give a valuation in a range between 0 and $€ 10$ (market price range). The maximum bidding price was set at $€ 10$, as this is roughly twice the price of any "notable" brand laundry detergent and almost three times the average price of a home brand laundry detergent of the same format (form, quantity, etc.). The $€ 10$ cap seemed a reasonable limit, because the target group of participants are regular buyers and probably they will rely on market prices as a reference for their valuation. The experiment was carried out in October and November 2011, with a total of 161 participants, $72 \%$ of them women ${ }^{10}$ and with an average age of 41 years. The experimental procedure is detailed below.

First, subjects were approached in a random fashion, only once during specific days ${ }^{11}$ in a higher educational institution. Potential participants were screened by asking whether in their household they were in charge of doing the laundry and buying laundry products. After introducing the research topic and gaining consent, participants were randomly designated to a treatment group.

Second, each participant received a written and an oral explanation about the procedure of the experiment and an example round was played with a different product (glass cleaning spray ${ }^{12}$ ) to check that the procedure was understood correctly. At this point, it was emphasized that in the factual round participants had to provide a valuation for two products, but only one product was going to be randomly selected by throwing a dice. The resulting product was binding and its valuation was to be compared with the "experimental" price produced by digital number generator. ${ }^{13}$

Third, participants provided a valuation for both products and to reduce potential order effects, participants' valuations of the products was randomized (Huffman et al. 2003).

10. Women in industrial societies are still mainly responsible for the household chores such as doing the laundry. This is a predominant pattern in the domestic division of labor (Geist 2005).

11. We ran the experiment on Mondays, Tuesdays, or Thursdays for reasons of staff availability.

12. For the illustration of the procedure a single product with a different brand was used to prevent bias related to priming.

13. The digital number generator used can be found online: http://rechneronline.de/randomnumbers/. Numbers (with two decimals) are randomly drawn in a range between 0 and 10 . 
Fourth, after throwing a dice to determine which of the products was selected, the participant presses the digital number generator and the resulting number was compared with the valuation given for the selected product. If the participants' valuation was equal to or higher than the number generated he/she received the product. If the participants' valuation for the product was lower than the generated number/artificial market price, he/she received a cash payment equal to the "price" produced by the number generator.

Finally, participants filled out a survey containing a number of control questions. The questionnaire included sociodemographic questions and a list of validated scales of perceived availability, PCE, attitudes, and behavioral intention toward sustainable products. The survey also included questions about the perceived importance of specific product characteristics such as structure or form of the product (e.g., gel, powder, etc.), strength/functional performance attributes (washing results, textile preservation, color maintenance, etc.), and other product perceptions (quality, outlook, functionality, and fashionability). ${ }^{14}$ The latter variables were included because they have been shown to have an influence on the valuation of products (Luchs et al. 2010).

\section{RESULTS}

In the analysis 160 respondents were included and one outlier was excluded. ${ }^{15}$ Table 1 presents a description of the treatments and variables used in the analysis and Table 2 displays the mean and median values of the relative premiums per group. The average premium (RPREMIUM) for the eco product (eco-labeled laundry detergent) varies between $6 \%$ in the control group (Group 0) and $22 \%$ in group $\mathrm{C} 1$, the group receiving information about the premium paid by the majority of previous participants (Conformist transmission eco).

To establish any statistical difference in the premiums between the different treatments and considering a possible correlation of the dependent variables (WTPE, WTPNE, and RPREMIUM) a MANOVA test was conducted. Table 3 presents the results of the multivariate and univariate tests, revealing a statistically significant effect of treatments (information groups) in the variation of the relative premiums [Wilks' $\lambda=0.793$,

14. Table 1 provides a description of the constructs and Table A2 in Appendix 1 presents the reliability tests.

15. This observation presented a WTP that was five standard deviations higher than the average WTP. 


\begin{tabular}{|c|c|}
\hline Treatment or Control Variable & Description \\
\hline Group 0 & Control group. Valuation of participants provided with no information. \\
\hline C1 & $\begin{array}{l}\text { Conformist transmission toward eco-products. Premium of participants receiving information stating that the } \\
\text { majority of the group paid more for the sustainable product. }\end{array}$ \\
\hline $\mathrm{C} 2$ & $\begin{array}{l}\text { Conformist transmission toward non-eco products. Premium of participants receiving information stating that } \\
\text { the majority of the group paid more for the conventional product. }\end{array}$ \\
\hline W1 & $\begin{array}{l}\text { Payoff-biased transmission toward eco-products. Premium of participants receiving information stating that a } \\
\text { "high status individual" of the group paid more for the sustainable option. }\end{array}$ \\
\hline W2 & $\begin{array}{l}\text { Payoff-biased transmission toward non-eco products. Premium of participants receiving information stating that } \\
\text { a "high status individual" of the group paid more for the conventional option. }\end{array}$ \\
\hline Age & Years \\
\hline Gender & Dummy variable: $0=$ male, $1=$ female. \\
\hline Education & Level of education in years. \\
\hline Children & Number of children. \\
\hline Detergent form (prod. characteristics) & Importance given to the detergent form (5-point Likert scale). \\
\hline Detergent price (prod. characteristics) & Importance given to the price of the detergent (5-point Likert scale). \\
\hline Price perception of sustainable products & Participants’ price perception of sustainable products “in general” as expensive (5-point Likert scale). \\
\hline \multirow[t]{2}{*}{ Strength attributes (functional performance)* } & $\begin{array}{l}\text { Measurement importance of strength/functional performance attributes consisting of three statements on a } \\
\text { 5-point Likert scale (Totally unimportant-unimportant-neutral-important-very important) }\end{array}$ \\
\hline & Items: Washing performance/textile conservation/color retention. \\
\hline \multirow[t]{2}{*}{ Positive prod. Perception* } & $\begin{array}{l}\text { Measurement positive perception of social and environmentally friendly products consisting of four items on a } \\
\text { 5-point Likert scale (Totally disagree-disagree-nor agree nor disagree-agree-totally agree) }\end{array}$ \\
\hline & Items: quality, outlook, functionality, and fashionability of sustainable products. \\
\hline Perceived consumer effectiveness (PCE)* & $\begin{array}{l}\text { Measurement PCE scale constructed by Roberts (1996) consisting of four items on a 5-point Likert scale } \\
\text { (Totally disagree-disagree-nor agree nor disagree-agree-totally agree) }\end{array}$ \\
\hline Family \& friends. & Participants reporting that family members or friends use/“buy” sustainable products. \\
\hline
\end{tabular}

*The reliability test for these constructs are displayed in Table A2, Appendix 1. 
Table 2: Relative (percentage) Premiums for Eco-laundry Detergent

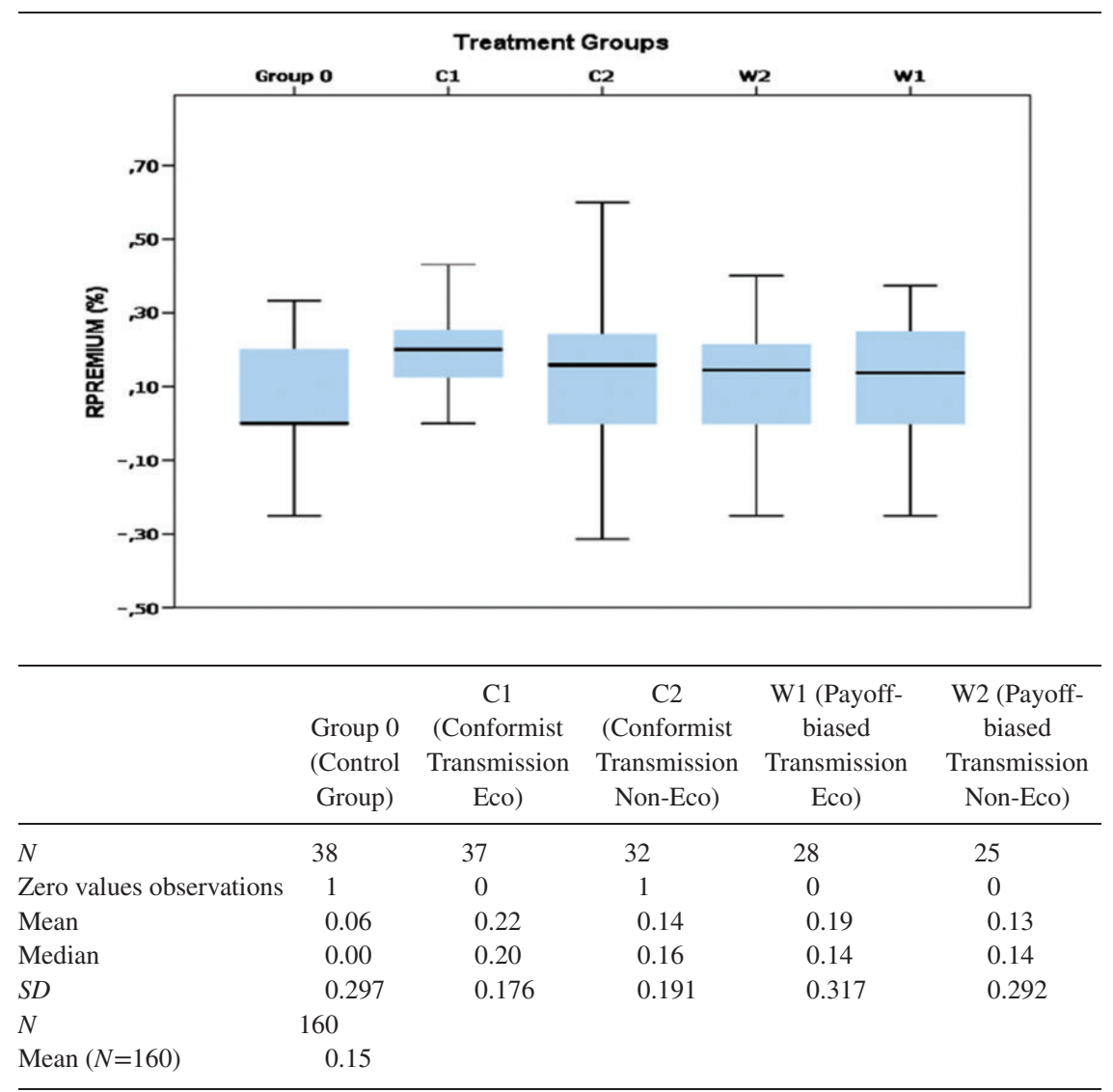

Note: Variables: Relative premium [(WTPE - WTPNE)/WTPNE].

$F(12,405.09)=3.01, p<.001$ and power to detect the effect $=0.984]$. Also the Kruskal-Wallis non-parametric test confirmed that the variation in the premium across the different groups is statistically significant (RPREMIUM: $\left.\chi^{2}(4)=13.44, p=.009\right)$.

The information provided to the groups seems to have an impact on the relative premiums paid for sustainable products. The subsequent ANOVA analysis reveals that there are differences in RPREMIUM between different groups $(F=2.132 ; p=.079)$. This analysis is followed by a Scheffe's post hoc test, which is also presented in Table 3 . A significant difference in RPREMIUM between participants that received information about the premium paid by the majority of their peers $(\mathrm{C} 1$ : conformist transmission eco product) and participants who did not receive any information or control 
Table 3: Summary of Multivariate and Univariate Analysis of Relative Differences in Premiums for Eco-laundry Detergent across Groups

\begin{tabular}{lcccc}
\hline MANOVA & & & & \\
\hline & Value & $F$ & Significance & $\begin{array}{c}\text { Observed } \\
\text { Power }^{\mathrm{a}}\end{array}$ \\
\hline Pillai's Criterion & 0.215 & 2.994 & $0.000^{* * * *}$ & 0.992 \\
Wilks' Lambda & 0.793 & 3.097 & $0.000^{* * * *}$ & 0.984 \\
Hotelling's Trace & 0.251 & 3.178 & $0.000^{* * * *}$ & 0.995 \\
Roy's GCR & 0.204 & 7.905 & $0.000^{* * *}$ & 0.998 \\
\hline
\end{tabular}

ANOVA

\begin{tabular}{lccccc}
\hline Dependent Variable & $\begin{array}{c}\text { Type III Sum } \\
\text { of Squares }\end{array}$ & DF & $F$ & Significance & $\begin{array}{c}\text { Observed } \\
\text { Power }^{\text {a }}\end{array}$ \\
\hline RPREMIUM & 0.565 & 4 & 2.132 & $0.079^{*}$ & 0.621 \\
WTPE & 30.622 & 4 & 6.994 & $0.000^{* * *}$ & 0.994 \\
WTPNE & 7.862 & 4 & 2.263 & $0.065^{*}$ & 0.651 \\
\hline
\end{tabular}

Scheffe Post Hoc test

\begin{tabular}{lccccc}
\hline $\begin{array}{l}\text { Dependent } \\
\text { Variable }\end{array}$ & $\begin{array}{c}\text { Group 0/Control } \\
\text { group (I) }\end{array}$ & $\begin{array}{c}\text { Treatment }^{\mathrm{b}} \\
(\mathrm{J})\end{array}$ & $\begin{array}{c}\text { Mean Difference } \\
(\mathrm{I}-\mathrm{J})\end{array}$ & $S E$ & Significance \\
\hline RPREMIUM & Group 0 & C1 & -0.164 & 0.056 & $0.048^{* *}$ \\
& Group 0 & C2 & -0.076 & 0.059 & 0.891 \\
& Group 0 & W1 & -0.128 & 0.077 & 0.654 \\
& Group 0 & W2 & -0.072 & 0.076 & 0.985 \\
\hline
\end{tabular}

Note: Dependent variables: RPREMIUM = [(WTPE-WTPNE)/WTPNE].

${ }^{\mathrm{a}}$ Computed using alpha $=0.05$.

${ }^{b}$ Treatments: C1 (Conformist transmission eco); C2 (Conformist transmission non-eco); W1 (Payoff-biased transmission eco) and W2 (Payoff-biased transmission non-eco)

$* 10 \%$ significance, $* * 5 \%$ significance, and $* * * 1 \%$ significance.

group (Group 0) can be observed. Interestingly, there are no statistically significant differences in relative premiums between the other treatments (C2: conformist transmission non-eco, W1: payoff-biased transmission eco, and W2: payoff-biased transmission non-eco) and the control group. Therefore, participants receiving information about the premium paid by a "high status" person in the group do not seem to make significantly different decisions (pay a higher/lower premium) compared to participants not receiving any information. Also, there are no statistically significant differences in the premiums between conformist and payoff-biased transmission treatments.

To corroborate the influence of the independent variable and the social influence treatments on the premium paid for sustainable products, 
Figure 1: (A) Distribution of WTP for Eco and Non-Eco Laundry Detergent and (B) Distribution of Absolute and Relative Premium for Eco Laundry Detergent
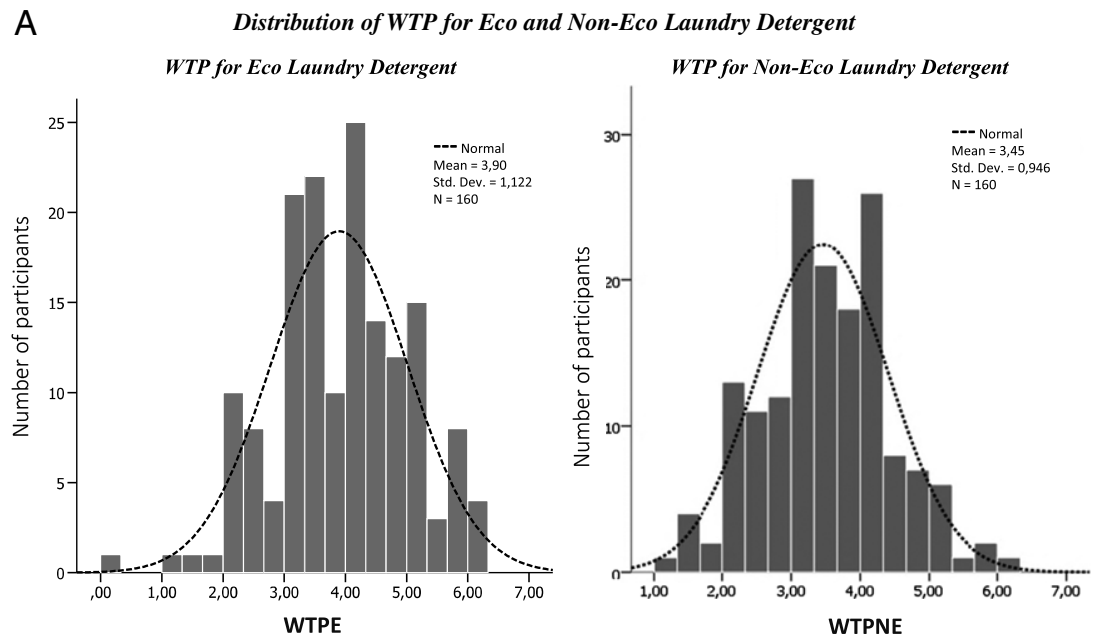

B

Distribution of Absolute and Relative Premium for Eco Laundry Detergent Absolute Premium (WTPE - WTPNE)
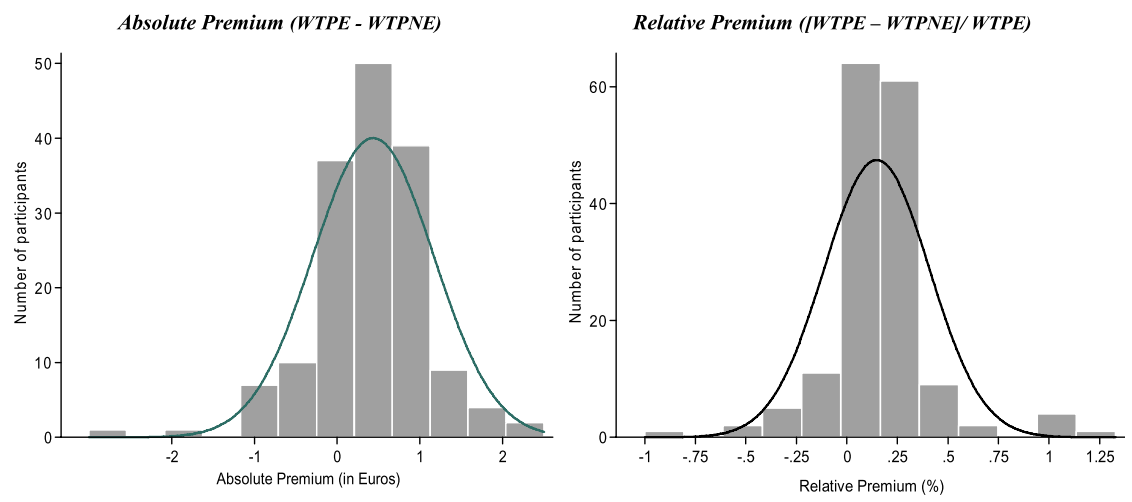

different Tobit censored regressions were conducted because some concentration at zero is observed in the distribution of premiums ${ }^{16}$ (see Figure 1). About $20 \%$ of the observations are zero premiums. Table 4 presents the regressions results, where Models 1 and 2 use the change score model to explain RPREMIUM without controlling for WTPNE. We add this control variable in Models 3 and 4, which follow the

16. Additionally, two regressions were performed using a WLS procedure as described by Kieschnick and McCullough (2003), which features percentages as dependent variables. The results are very similar to the Tobit regressions. 
Table 4: Tobit Relative Premiums for Eco-laundry Detergent

\begin{tabular}{|c|c|c|c|c|}
\hline \multirow[b]{2}{*}{ Variables } & \multicolumn{2}{|c|}{$\begin{array}{l}\text { Models Using the } \\
\text { Change Score Method }\end{array}$} & \multicolumn{2}{|c|}{$\begin{array}{l}\text { Models Using the } \\
\text { Regressor Variable Method }^{\mathrm{a}}\end{array}$} \\
\hline & $\begin{array}{l}\text { Model } 1 \\
\text { Coefficients }\end{array}$ & $\begin{array}{l}\text { Model } 2 \\
\text { Coefficients }\end{array}$ & $\begin{array}{l}\text { Model } 3 \\
\text { Coefficients }\end{array}$ & $\begin{array}{c}\text { Model } 4 \\
\text { Coefficients }\end{array}$ \\
\hline Constant & -0.189 & -0.427 & 0.199 & 0.038 \\
\hline WTPNE & & & $-0.092^{* * *}$ & $-0.110^{* * *}$ \\
\hline Age & 0.003 & 0.004 & 0.003 & $0.004^{*}$ \\
\hline Female & $0.124^{* *}$ & $0.119^{* *}$ & $0.123^{* *}$ & $0.113^{* *}$ \\
\hline Children & $-0.032^{*}$ & $-0.034^{*}$ & -0.027 & -0.028 \\
\hline Education & 0.004 & 0.007 & -0.001 & 0.001 \\
\hline Form detergent & 0.038 & $0.047^{*}$ & 0.032 & $0.041^{*}$ \\
\hline Price detergent & 0.010 & 0.014 & 0.021 & 0.029 \\
\hline $\begin{array}{l}\text { Strength attributes (functional } \\
\text { performance) }\end{array}$ & $-0.038^{*}$ & $-0.047^{* *}$ & $-0.032^{*}$ & $-0.41^{* *}$ \\
\hline Price perception sustainable products & -0.015 & -0.018 & -0.024 & -0.033 \\
\hline Positive prod. perception & $0.074^{* * *}$ & $0.072^{* * *}$ & $0.068^{* * *}$ & $0.067^{* * *}$ \\
\hline PCE & $-0.055^{* *}$ & $-0.042^{*}$ & $-0.046^{*}$ & -0.032 \\
\hline $\mathrm{C} 1$ (Conformist transmission eco) & & $0.201^{* * * *}$ & & $0.254^{* * *}$ \\
\hline $\begin{array}{l}\text { C2 (Conformist transmission } \\
\text { non-eco) }\end{array}$ & & 0.095 & & 0.077 \\
\hline W1 (Payoff transmission eco) & & 0.099 & & $0.132^{* * *}$ \\
\hline W2 (Payoff transmission non-eco) & & $0.149^{*}$ & & $0.165^{* *}$ \\
\hline Family \& friends & & $0.090^{* *}$ & & $0.089^{* *}$ \\
\hline $\mathrm{N}$ (uncensored) & $158(110)$ & $158(110)$ & $158(110)$ & $158(110)$ \\
\hline Log likelihood & -39.08 & -28.37 & -30.34 & -15.17 \\
\hline $\begin{array}{l}\text { Likelihood-ratio test: } \chi^{2} \\
\text { (probability) }\end{array}$ & 39.02 & $34.69(0.00)$ & $56.51(0.00)$ & $77.84(0.00)$ \\
\hline Pseudo $R^{2}$ & 0.33 & 0.48 & 0.48 & 0.69 \\
\hline
\end{tabular}

${ }^{\mathrm{a}}$ These results are also similar when applying a WLS regression.

$* 10 \%$ significance, $* * 5 \%$ significance, and $* * * 1 \%$ significance.

standard regressor variable method. In the theoretical part of this study, it was argued that models in which individual characteristics and peer influence variables are combined would lead to a more complete explanation of the premium and its variation. To test this empirically, we distinguish two groups of models. In the first group of models (Models 1 and 3) only individual characteristics are included as independent variables (attitudes, sociodemographic characteristics, etc.). The second group of models (Models 2 and 4) incorporates also the variables of social influence (treatments for conformist and payoff-biased transmission). Hence, the latter models test for the combined effect. In both cases, the inclusion of the social influence variables increases the explanatory power of the models. For example, in the case of Models 1 and 2, the predicted 
values and RPREMIUM share 48\% of the variance (McFadden's pseudo $R$-square $=0.48$ ), which is 15 points higher than the model without the social influence variables (Pseudo $R^{2}=0.33$ ). Therefore, it is clear that social influence plays a non-trivial role in the premium variation of sustainable products. Additionally, the impact of conformist transmission for the eco product is confirmed. The beta coefficients of the variable testing for conformist transmission (C1) in Models 2 and 4 show that participants paid more for the eco product $(\beta=0.20, p<.001)$ when they were informed that their peers had paid a higher premium for the eco-labeled laundry detergent than when participants did not receive any information. Also, the beta coefficient of the variable testing for payoff-biased transmission for the non-eco product (W2) is statistically significant. Surprisingly, participants paid a higher premium for the eco product when they were informed that their team manager ("high status individual") had paid more for the non-eco product. Lastly, indirect evidence of social influence from other social groups is found through the "family and friends" variable, showing that participants who reported that family members or friends use eco-products are willing to pay a higher premium for the eco-laundry product than participants reporting otherwise $(\beta=0.09$, $p<.05)$.

Consequently, $\mathrm{H} 1$ is confirmed, as there is evidence of conformist transmission when the information concerns the eco product (positive information). H2 cannot be totally rejected, as the premium for sustainable products was not significantly different than the premium paid by participants not receiving any information about their peers. However, the Mann-Whitney $U$ test showed that the relative premium paid for the eco product between $\mathrm{C} 1$ (conformist transmission eco) and $\mathrm{C} 2$ (conformist transmission non-eco) was significantly different $(Z=-1.838$; $0.066, p<.1)$. Thus, the premium for the sustainable product remains small if the participants' peers favored conventional products. On the other hand, we have to be cautious about $\mathrm{H} 3$, since the evidence is not conclusive. In Model 2 this treatment is not significant, while Model 4 (see Table 4) evidences that participants paid a higher premium for the eco product, when they were informed that the "high status" individual in their group had paid more for this product (payoff-biased transmission for the eco prod$u c t$ ). Regarding $\mathrm{H} 4$, the evidence shows that participants are willing to pay a premium for the eco product even though the "high status" individual in their group is doing otherwise. However, this effect is rather weak (significant at $10 \%$ only) compared to $\mathrm{H} 1$.

In line with previous WTP studies (e.g., Drozdenko, Jensen, and Coelho 2011; Loureiro, McCluskey, and Mittelhammer 2002), a gender effect is 
observed as well. Female participants are willing to pay more for the eco-laundry detergent than male participants $(\beta=0.12, p<.05)$. Likewise, the control variables included on the effects of product characteristics and consumer perceptions have a different degree of influence in the valuation of the eco-labeled laundry product. Variables that influence the relative premium for the eco-product include "Positive product perception ${ }^{17}$ " and the importance that respondents attach to the form of the product (gel, powder, liquid, etc.). In the first case, participants who have a positive perception of the product (quality, outlook, functionality, and fashionability) paid more than participants who have a negative perception $(\beta=0.07, p<.001)$. Participants who do not lend high importance to the form of the detergent are also willing to pay a higher premium for the eco-product $(\beta=0.04$, $p<.1$ ). In contrast, a high valuation of strength or functional performance attributes has a negative effect on the premium for the environmentally friendly product. As a result, participants demanding a high functional performance (clean washing results) are less willing to pay a premium for the eco-product than those who do not focus on high functional performance $(\beta=-0.05, p<.05)$. Finally, among the attitudinal variables, a low PCE has a significant negative effect on the premium for the eco-product. Therefore, participants who do not believe that through their buying behavior they can help the environment (PCE) are less willing to pay a premium for the eco-product than participants who have a positive PCE $(\beta=-0.04, p<.1)$.

\section{CONCLUSIONS}

From the results of the analysis we can first conclude that there is strong evidence of a conformist transmission in the WTP for the eco product, because participants who were informed that the majority of their peers had paid a higher premium for the eco product (past behavior), were also willing to pay more for it in the present. Also, the control variable for the influence of an alternative social group, "Family and friends," presents evidence of social influence on the valuation. Participants reporting that family members or friends use eco products were willing to pay a higher premium for the eco-laundry detergent than those reporting otherwise. This evidence shows that the social actors in the environment of consumers can positively influence the amount they are willing to pay for sustainable products, when the past behavior of other consumers

17. The reliability tests for this and the other attitudinal constructs are displayed in Table A2, Appendix 1. 
is used as a reference. This effect is found on top of the effects of individual characteristics, which so far served as the main explanations for the WTP and the subsequent premium. However, we have to be cautious because the payoff-biased transmission eco treatment (W1) was not statistically significant across all models, although it has the expected sign. This does not mean, however, that we can rule out payoff-biased transmission, because the selected role model ("high status individual") may not be the ideal reference person for this type of decision or product category.

Some studies in the past have shown that higher paid colleagues are important referents for buying positional goods (Frank 1985), but laundry detergents are distinctly non-positional. Further, the significant results of the treatment payoff-biased transmission toward non-sustainable products (W2) may be driven by reputation and status seeking motives, as a way to build a pro-social reputation and prestige in the group. Griskevicius, Tybur, and van den Bergh (2010) found evidence that status motives increase the consumers' tendencies to choose sustainable products. It might appear contradictory, but from a "status signaling perspective" it is important to recall that altruism is partially associated with status because altruistic displays can be used to signal a person's wealth or ethical superiority. Therefore, participants who reported a higher premium for the eco product when informed that their team manager ("high status individual") had paid more for the non-eco product, may thus (try to) appear more pro-social/sustainable for self-serving reasons. Another possible explanation may lie in the group differences in identification with the principles or cause of the chosen high status person (team manager). Also, these results may be linked to specific contextual differences, such as temporal group dynamics (e.g., sequencing of leader behaviors as mentioned by Casimer 2001) or gender proportions and performance evaluation (Pazy and Oron 2001).

Regarding the case of "Conformist transmission for non-eco-product" (C2), where participants received information stating that the majority had paid more for the non-eco product, no conclusive effect was found. The premium for non-eco products did not increase substantially when participants knew that their peers paid more for this product. A possible explanation for this result may be that conventional products are better known by consumers. They might have expected different information like a lower premium or a zero premium as they are better informed about the actual prices of such products. Tentatively, the latter could have caused a cognitive dissonance effect (Festinger 1957), leading participants to disregard, totally or partially, information from others/peers 
and to base their valuation on their own information and experience. However, these results show that positive information seems to be more influential than negative information. This result is in line with previous findings showing that people are more inclined to diffuse positive rather than negative information by word-of-mouth (WOM) (Naylor and Kleiser 2000).

Finally, the average relative premium (15\%), varying from $6 \%$ in Group 0 and 22\% in Group C1 (see Table 2), is slightly lower than the premium found in previous studies such as Bjørner, Hansen, and Russell (2004) among Danish consumers, which calculated a premium of $17 \%$ for eco-labeled detergents. ${ }^{18}$ Also, Hopkins and Roche (2009) reported a somewhat higher premium for home cleaning products. These relatively small discrepancies might be explained by the fact that sustainable or ethical related attributes do not have a uniformly positive or negative influence on consumer preferences, if we assume that the valuation of sustainable attributes differs across product categories. Hence, in the case of products where strength (functional performance) attributes are important, sustainable attributes may not be valued and the presence of them might lead to a negative judgment about their functional performance. Luchs et al. (2010) present evidence in this regard, showing that valuation of sustainability attributes depends on the type of benefit valued in the product category.

In the case of products where strength attributes are valued, such as laundry detergents, liquid hand sanitizer, and automobile tires, sustainability attributes negatively affect consumer preferences. This explanation is partly supported by the finding that those individuals that were more focussed on strength or high functional attributes (functional performance), reported a lower premium than those who are less demanding on this aspect (see Table 4). Another possible explanation might be that positive social information has a stronger effect than less positive information, given that the average premiums for treatments C1 and W1 (22\% and 19\%), as well as for C2 and W2 (14\% and 13\%), are close to each other. Thus, a positive premium paid for eco-products may be perceived as more revealing and therefore participants (in treatments $\mathrm{C} 1$ and W1) are more motivated to pay a higher premium when others are doing so. A higher premium for non-eco products has a weaker effect, because participants' familiarity with the product attenuates their perception about the diagnostic value of the information provided. East, Hammond, and Lomax (2008) found evidence

18. In this study, the premium for different brand detergents carrying the Nordic Swan eco-label is considered. 
showing that the positive information has a stronger impact than negative information on the probability of product purchase.

The findings concerning conformist transmission toward eco-products (treatment C1) and payoff-biased transmission for non-eco products (W2) lend support to our hypothesis that the behavior of others has an effect on the WTP for sustainable products. Put differently, social influence plays a role in the premium variation of sustainable products, as witnessed by the fact that the multiple square correlation in the regressions increases once we include these variables alongside conventional independent variables (environmental attitudes, socioeconomic characteristics, etc.). The predicted values share about $48 \%$ of the variance (Pseudo $R^{2}=0.48$ ), which is $15 \%$ more than the model considering only conventional independent variables. Therefore, the variation in the premium is better explained when social effects are included. This is an important aspect to consider, especially when selecting advertising models that make use of pre-existing social networks. Here it would be important to consider the use of WOM and product sampling to increase positive signals (social influence) toward specific sustainable products.

\section{LIMITATIONS AND FUTURE RESEARCH}

We analyzed the impact of social influence on the premium for a specific eco-product, where it should be recognized that the social effects may vary with product category and consumer segment, because consumers attach different values to the functional characteristics and social meaning (symbolism) of products. Therefore, the relative weight given to the information coming from social groups may vary as well. For example, the salience of a particular reference person ("high status individual") may increase with this person's (perceived) level of expertise on relevant product attributes. Further research is needed to clarify differences across categories and segments. At the same time, we believe that our results are representative for products whose strength (functional performance) is highly valued. More important perhaps, our results reinforce the need for further research into WTP of sustainable products, since the availability and pricing of sustainable products is increasing in importance and at the same time is relatively intricate. In this sense, there are various possibilities for future research, such as further evaluation of the effects of altruistic and utilitarian messages on the premiums for sustainable products and the influence of digital WOM and other alternative communication strategies on the valuation and demand for sustainable products. 


\section{APPENDIX 1}

Table A1.1: Descriptives

\begin{tabular}{lcccc}
\hline Product & Category & $N$ & Median & $S D$ \\
\hline Fish & 0 & 25 & 4.00 & 0.637 \\
& 1 & 20 & 3.00 & 0.988 \\
Toilet paper & 0 & 25 & 3.00 & 0.925 \\
& 1 & 20 & 3.00 & 1.050 \\
LED lamp & 0 & 25 & 2.00 & 1.159 \\
& 1 & 20 & 2.00 & 1.268 \\
\hline
\end{tabular}

Table A1.2: Hypothesis Test summary

\begin{tabular}{|c|c|c|c|c|c|c|}
\hline & Null Hypothesis & Test & Sig. & Decision & & \\
\hline 1 & $\begin{array}{l}\text { The distribution of } \\
\text { Degree of } \\
\text { environmental } \\
\text { friendliness "Fish" } \\
\text { is the same across } \\
\text { categories of } \\
\text { respondents without } \\
\text { and with stimulus }\end{array}$ & $\begin{array}{l}\text { Independent } \\
\text { Samples } \\
\text { Mann- } \\
\text { Whitney } U \\
\text { Test }\end{array}$ & 0.84 & $\begin{array}{l}\text { Reject Null } \\
\text { Hypothesis }\end{array}$ & $\begin{array}{l}\text { Total N } \\
\text { Mann- } \\
\text { Whitney } U \\
\text { Wilcoxon W } \\
\text { Test } \\
\quad \text { Statistic } \\
\text { Standard } \\
\quad \text { Error }\end{array}$ & 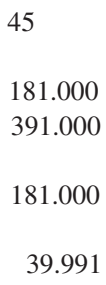 \\
\hline 2 & $\begin{array}{l}\text { The distribution of } \\
\text { Degree of } \\
\text { environmental } \\
\text { friendliness "Toilet } \\
\text { paper" is the same } \\
\text { across categories of } \\
\text { respondents without } \\
\text { and with stimulus }\end{array}$ & $\begin{array}{l}\text { Independent } \\
\text { Samples } \\
\text { Mann- } \\
\text { Whitney } U \\
\text { Test }\end{array}$ & 0.547 & $\begin{array}{l}\text { Retain } \\
\text { the null } \\
\text { hypothesis. }\end{array}$ & $\begin{array}{l}\text { Standardized Test } \\
\text { Statistic } \\
\text { Asymptotic Sig. } \\
\quad \text { (2-sided test) }\end{array}$ & $\begin{array}{r}-1.725 \\
0.084\end{array}$ \\
\hline 3 & $\begin{array}{l}\text { The distribution of } \\
\text { Degree of } \\
\text { environmental } \\
\text { friendliness "LED } \\
\text { lamp" is the same } \\
\text { across categories of } \\
\text { respondents without } \\
\text { and with stimulus }\end{array}$ & $\begin{array}{l}\text { Independent } \\
\text { Samples } \\
\text { Mann- } \\
\text { Whitney } U \\
\text { Test }\end{array}$ & 0.763 & $\begin{array}{l}\text { Retain } \\
\text { the null } \\
\text { hypothesis. }\end{array}$ & & \\
\hline
\end{tabular}


Figure A1: Change in Perception About Product Environmentally Friendliness

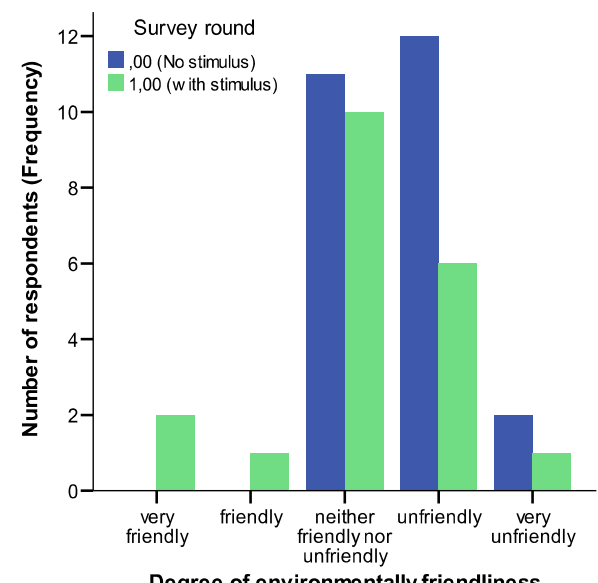

(Fish)

Figure A2: Vignettes

Vignettes

Treatment 1: Conformist trans.eco product

The majority of the previous participants in this experiment from " $X$ " paid more for this product.

Treatment 2: Conformist trans. non-eco product

The majority of the previous participants in this experiment from " $X$ " paid more for this product.

Treatment 3: Pay off biased trans. eco product

The team manager of " $X$ " paid more for this product.

Treatment 4: Pay off biased trans. non-eco product

The team manager of " $X$ " paid more for this product. 
Table A2: Reliability Statistics

\begin{tabular}{lccc}
\hline Construct & Mean & $S D$ & Cronbach's alpha \\
\hline Positive product perception of sustainable products & 3.54 & 0.56 & 0.60 \\
Strength attributes (functional performance) & 4.48 & 0.45 & 0.89 \\
Perceived consumer effectiveness (PCE) & 2.02 & 0.74 & 0.69 \\
\hline
\end{tabular}

\section{REFERENCES}

Aryal, Kamal P., Pashupati Chaudhary, Sangita Pandit, and Govinda Sharma. 2009. Consumers' Willingness to Pay for Organic Products: A Case from Kathmandu Valley. The Journal of Agriculture and Environment, 10 (June): 12-21.

Bearden, William O., Richard G. Netemeyer, and Jesse E. Teel. 1989. Measurement of Consumer Susceptibility to Interpersonal Influence. Journal of Consumer Research, 15 (3): 473-481.

Bjørner, Thomas B., Lars G. Hansen, and Clifford S. Russell. 2004. Environmental Labeling and Consumers' Choice - An Empirical Analysis of the Effect of the Nordic Swan. Journal of Environmental Economics and Management, 47 (3): 411-434.

Burnkrant, Robert E. and Alain Cousineau. 1975. Informational and Normative Social Influence in Buyer Behavior. Journal of Consumer Research, 2 (3): 206-215.

Casimer, Gian. 2001. Combinative Aspects of Leadership Style: The Ordering and Temporal Spacing of Leadership Behaviors. Leadership Quarterly, 12 (3): 245-278.

Cason, Timothy N. and Lata Gangadharan. 2002. Environmental Labeling and Incomplete Consumer Information in Laboratory Markets. Journal of Environmental Economics and Management, 43 (1): 113-134.

Chen, Al Y.S., Roby B. Sawyers, and Paul F. Williams. 1997. Reinforcing Ethical Decision Making Through Corporate Culture. Journal of Business Ethics, 16 (8): 855-865.

Chen, Yi-Fen. 2008. Herd Behavior in Purchasing Books Online. Computers in Human Behavior, 24 (5): 1977-1992.

Childers, Terry L. and Akshay R. Rao. 1992. The Influence of Familial and Peer-based Reference Groups on Consumer Decisions. Journal of Consumer Research, 19 (2): 198-211.

Childers, Courtney C., Eric Haley, and Lisa Jahns. 2011. Insights into University Freshman Weight Issues and How They Make Decisions About Eating. The Journal of Consumer Affairs, 45 (2): 306-328.

Cocanougher, Benton and Grady D. Bruce. 1971. Socially Distant Reference Groups and Consumer Aspirations. Journal of Marketing Research, 8 (3): 379-381.

Corrigan, Jay R. and Matthew C. Rousu. 2006. Posted Prices and Bid Affiliation: Evidence from Experimental Auctions. American Journal of Agricultural Economics, 88 (4): 1078-1090.

Demont, Matty, Espérance Zossou, Pieter Rutsaert, Maimouna Ndour, Paul Van Mele, and Wim Verbeke. 2012a. Consumer Valuation of Improved Rice Parboiling Technologies in Benin. Food Quality and Preference, 23 (1): 63-70.

Demont, Matty, Pieter Rutsaert, Maïmouna Ndour, Wim Verbeke, Papa Abdoulaye Seck, and Eric Tollens. 2012b. Experimental Auctions, Collective Induction and Choice Shift: Willingness-to-Pay for Rice Quality in Senegal. European Review of Agricultural Economics, 40 (2): 261-286.

Drozdenko, Ronald, Marlene Jensen, and Donna Coelho. 2011. Pricing of Green Products: Premiums Paid, Consumer Characteristics and Incentives. International Journal of Business, Marketing, and Decision Science, 4 (1): 106-114.

Dubois, Bernard and Patrick Duquesne. 1993. The Market for Luxury Goods: Income Versus Culture. European Journal of Marketing, 27 (1): 35-44. 
East, Robert, Kathy Hammond, and Wendy Lomax. 2008. Measuring the Impact of Positive and Negative Word of Mouth on Brand Purchase Probability. International Journal of Research in Marketing, 25 (3): 215-224.

Efferson, Charles, Peter J. Richerson, Richard McElreath, Mark Lubell, Ed Edsten, Timothy M. Waring, Brian Paciotti, and William Baum. 2007. Learning, Productivity, and Noise: An Experimental Study of Cultural Transmission on the Bolivian Altiplano. Evolution and Human Behavior, 28 (1): $11-17$.

Falk, Armin and Markus Knell. 2004. Choosing the Joneses: Endogenous Goals and Reference Standards. The Scandinavian Journal of Economics, 106 (3): 417-435.

Festinger, Leon. 1957. A Theory of Cognitive Dissonance. Stanford, CA: Stanford University Press.

Filstad, Cathrine. 2004. How Newcomers Use Role Models in Organizational Socialization. Journal of Workplace Learning, 16 (7): 396-409.

Frank, Robert H. 1985. Choosing the Right Pond: Human Behavior and the Quest for Status. Oxford: Oxford University Press.

Geist, Claudia. 2005. The Welfare State and the Home: Regime Differences in the Domestic Division of Labour. European Sociological Review, 21 (1): 23-41.

Goodrich, Kendall and Tamara F. Mangleburg. 2010. Adolescent Perceptions of Parent and Peer Influences on Teen Purchase: An Application of Social Power Theory. Journal of Business Research, 63 (2): 1328-1335.

Goldenberg, Jacob, Sangman Han, Donald R. Lehmann, and Jae W. Hong. 2009. The Role of Hubs in the Adoption Process. Journal of Marketing, 73 (2): 1-13.

Granovetter, Mark. 1985. Economic Action and Social Structure. The Problem of Embeddedness. American Journal of Sociology, 91 (3): 481-510.

Griskevicius, Vladas, Joshua M. Tybur, and Bram van den Bergh. 2010. Going Green to Be Seen: Status, Reputation and Conspicuous Conservation. Journal of Personality and Social Psychology, 98 (3): 392-404.

Harrison, Glenn W., Ronald M. Harstad, and E. Elisabet Rutström. 2004. Experimental Methods and Elicitation of Values. Experimental Economics, 7 (2): 123-140.

Henrich, Joe and Robert Boyd. 1998. The Evolution of Conformist Transmission and the Emergence of Between-Group Differences. Evolution and Human Behavior, 19 (4): 215-241.

Henrich, Joseph and Robert Boyd. 2001. Why People Punish Defectors: Weak Conformist Transmission Can Stabilize Costly Enforcement of Norms in Cooperative Dilemmas. Journal of Theoretical Biology, 208 (1): 79-89.

Hopkins, Michael and Catherine Roche. 2009. What the 'Green' Consumer Wants. MIT Sloan Management Review, 50 (4): 87-89(Reprint 50415).

Howarth, Richard B. and Matthew A. Wilson. 2006. A Theoretical Approach to Deliberative Evaluation: Aggregation by Mutual Consent. Land Economics, 82 (1): 1-16.

Hu, Wuyang, Timothy Woods, and Sandra Bastin. 2009. Consumer Acceptance and Willingness to Pay for Blueberry Products with Nonconventional Attributes. Journal of Agricultural and Applied Economics, 41 (1): 47-60.

Huffman, Wallace E., Jason F. Shogren, Matthew C. Rousu, and Abebayehu Tegene. 2003. Consumer Willingness to Pay for Genetically Modified Food Labels in a Market with Diverse Information: Evidence from Experimental Auctions. Journal of Agricultural and Resource Economics, 28 (3): 481-502.

Katz, Elihu. 1957. The Two-step Flow of Communication: An Up-to-date Report on a Hypothesis. Public Opinion Quarterly, 21 (1): 61-78.

Kelley, Harold H. 1947. Two Functions in Reference Groups. In Readings in Social Psychology, edited by Guy E. Swanson, Theodore E. Newcomb, and Eugene L. Hartley (410-414). New York: Holt, Rinehart and Winston.

Kieschnick, Robert and Bruce D. McCullough. 2003. Regression Analysis of Variates Observed on (0,1): Percentages, Proportions and Fractions. Statistical Modelling, 3 (3): 193-213.

List, John A., Robert P. Berrens, Alok K. Bohara, and Joe Kerkvliet. 2004. Examining the Role of Social Isolation on Stated Preferences. The American Economic Review, 94 (3): 741-752. 
Loureiro, Maria L. and Susan Hine. 2002. Discovering Niche Markets: A Comparison of Consumer Willingness to Pay for Local (Colorado Grown), Organic, and GMO-free Products. Journal of Agricultural and Applied Economics, 34 (3): 477-487.

Loureiro, Maria L., Jill J. McCluskey, and Ron C. Mittelhammer. 2002. Will Consumers Pay a Premium for Eco-labeled Apples? The Journal of Consumer Affairs, 36 (2): 203-219.

Loureiro, Maria L. and Justus Lotade. 2005. Do Fair Trade and Eco-labels in Coffee Wake Up the Consumer Conscience? Ecological Economics, 53 (1): 129-138.

Luchs, Michael G., Rebecca Walker Naylor, Julie R. Irwin, and Rajagopal Raghunathan. 2010. The Sustainability Liability: Potential Negative Effects of Ethicality on Product Preference. Journal of Marketing, 74 (4): 18-31.

Lusk, Jayson L., Corinne Alexander, and Matthew C. Rousu. 2007. Designing Experimental Auctions for Marketing Research: The Effect of Values, Distributions, and Mechanisms on Incentives for Truthful Bidding. Review of Marketing Science, 5 (1): 1-32.

Michaud, Céline and Daniel Llerena. 2011. Green Consumer Behaviour: An Experimental Analysis of Willingness to Pay for Remanufactured Products. Business Strategy and the Environment, 20 (6): 408-420.

Moore, Elizabeth S., William L. Wilkie, and Richard J. Lutz. 2002. Passing the Torch: Intergenerational Influences as Source of Brand Equity. Journal of Marketing, 66 (2): 17-37.

Moretti, Enrico. 2011. Social Learning and Peer Effects in Consumption: Evidence from Movie Sales. Review of Economic Studies, 78 (1): 356-393.

Naylor, Gillian and Susan Bardi Kleiser. 2000. Positive Versus Negative Word-of-Mouth: An Exception to the Rule. Journal of Consumer Satisfaction, Dissatisfaction and Complaining Behavior, 13 (1): 26-36.

Ocasio, William. 2011. Attention to Attention. Organization Science, 22 (5): 1286-1296.

Pazy, Asya and Israela Oron. 2001. Sex Proportion and Performance Evaluation Among High-Ranking Military Officers. Journal of Organizational Behavior, 22 (6): 689-702.

Pearce, John A., Tracy R. Kramer, and D. Keith Robbins. 1997. Effects of Managers' Entrepreneurial Behavior on Subordinates. Journal of Business Venturing, 12 (2): 147-160.

Pelsmacker, Patrick De., Liesbeth Driesen, and Glenn Rayp. 2005. Do Consumers Care About Ethics? Willingness to Pay for Fair-Trade Coffee. The Journal of Consumer Affairs, 39 (2): 363-385.

Radam, Alias, Mohd R. Yacob, Than S. Bee, and Jinap Selamat. 2010. Consumers' Perceptions, Attitudes and Willingness to Pay Towards Food Products with "No Added MSG" Labeling. International Journal of Marketing Studies, 2 (1): 65-77.

Roberts, James A. 1996. Green Consumers in the 1990s: Profile and Implications for Advertising. Journal of Business Research, 36 (3): 217-231.

Roe, Brian, Mario F. Teisl, Alan Levy, and Matthew Rusell. 2001. US Consumers' Willingness to Pay for Green Electricity. Energy Policy, 29 (11): 917-925.

Shen, Junyi and Tatsuyoshi Saijo. 2007. Does an Energy Efficiency Label Alter Consumers' Purchasing Decisions? A Latent Class Approach Based on a Stated Choice Experiment in Shanghai. Journal of Environmental Management, 90 (11): 3561-3573.

Shen, Junyi. 2012. Understanding the Determinants of Consumers' Willingness to Pay for Eco-Labeled Products: An Empirical Analysis of the China Environmental Label. Journal of Service Science and Management, 5 (1): 87-94.

Stern, Barbara B. and Marla Royne Stafford. 2006. Individual and Social Determinants of Winning Bids in Online Auctions. Journal of Consumer Behaviour, 5 (1): 43-55.

Trudel, Remi and June Cotte. 2009. Does It Pay to Be Good? MIT Sloan Management Review, 50 (2): 61-68.

Valentine, Sean and Tim Barnett. 2002. Ethics Codes and Sales Professionals' Perceptions of Their Organizations' Ethical Values. Journal of Business Ethics, 40 (3): 191-200.

Weeds, Helen. 2012. Superstars and the Long Tail: The Impact of Technology on Market Structure in Media Industries. Information Economics and Policy, 24 (2): 60-68. 
Young, William, Kumju Hwang, Seonaidh McDonald, and Caroline J. Oates. 2010. Sustainable Consumption: Green Consumer Behavior When Purchasing Products. Sustainable Development, 18 (1): 20-31.

Yue, Chengyan, Charles R. Hall, Bridget K. Behe, Benjamin L. Campbell, Roberto G. Lopez, and Jennifer Dennis. 2010. Are Consumers Willing to Pay More for Biodegradable Containers than for Plastic Ones? Evidence from Hypothetical Conjoint Analysis and Nonhypothetical Experimental Auctions. Journal of Agricultural and Applied Economics, 42 (4): 757-772.

Yung, Yau. 2012. Willingness to Pay and Preferences for Green Housing Attributes in Hong Kong. Journal of Green Building, 7 (2): 137-152. 